$\xi=2$ 줄

\title{
Estimation of inferior alveolar nerve proximitytothe root apices : A CBVI analysis
}

\author{
S. S. Pagare ${ }^{1 *}$, Christine Roy ${ }^{2}$, Sonal Vahanwala ${ }^{3}$, Kapil Gavand ${ }^{4}$, Mandavi Waghmare ${ }^{5}$, Saurabh Goyal ${ }^{6}$ \\ ${ }^{1}$ Professor \\ ${ }^{2}$ Post graduate \\ ${ }^{3}$ Professor \\ ${ }^{4}$ Lecturer \\ ${ }^{5}$ Professor \& Head \\ ${ }^{6}$ Associate Professor \\ *Corresponding author E-mail: professorpagare@gmail.com
}

\begin{abstract}
A sound knowledge of the relative three dimensional (3D) approximations to the inferior alveolar nerve (IAN) to the root apices of the mandibular premolars and molars and their significance to gender and age is imperative for any dental procedure. Utilization of Cone Beam Computed Tomography (CBCT) has facilitated increased accuracy, higher resolution, and scan time and dose reduction. Literature reveals that various procedures in endodontics and oral surgery may lead to IAN injury, a rare but serious treatment complication. It can result from over instrumentation, periapical surgery and over filling by root canal obturation materials. Surgical endodontic procedures require a thorough knowledge of anatomic structures that might be traumatized. What better view than CBCT, where it gives a thorough knowledge about the $3 \mathrm{D}$ position of the IAN, allowing 3D reconstruction in true 1:1 anatomic representation. Majority of IAN injury cases reported were in relation to the mandibular second molars hence before undertaking procedures with potential damage to the IAN, it is essential to know the location of the IAN with respect to the surrounding structures to avoid injury or harm. A study was undertaken with an aim to assess the distance between the apical tips of the mesial roots of the first, second molars and second premolars to the superior border of the IAN. The findings of which could be used to prevent injuries to the inferior alveolar nerve.
\end{abstract}

Keywords: Inferior Alveolar Nerve (IAN); Cone Beam Computed Tomography (CBCT); Mandibular Posteriors

\section{Introduction}

Anatomy teaches us to acknowledge the inferior alveolar nerve (IAN).The inferior alveolar nerve is a branch of the mandibular nerve which is itself the third branch of the trigeminal nerve. Located within the mandibular canal, originating from the mandibular foramen, it descends into the ramus of the mandible obliquely and horizontally into the body of the mandible into the mental foramen (Carter RB et al. 1971' [1]. The mental nerve -nerve anterior to the mental foramen, is seen usually in the second premolar region. Branches of the inferior alveolar nerve continue from the premolar region to innervate the surrounding structures of the mandible (Claeys Vet al. 2005) [2].Iatrogenic injury to the mandibular nerve remains as an issue to the dental practitioners as the exact position of the IAN bundle varies from individual to individual. The proximity of the IAN bundle to the roots of the mandibular premolar and molar teeth may pose a potential risk of injury during any dental procedures.

A variety of dental procedures cause inferior alveolar nerve injury, which includes: local anaesthetic injections, third molar surgery, endodontics, trauma, orthognathic surgery and implants (Tara Renton et al. 2010) [3]. Any injuries to the nerve are associated with pain, hyperesthesia, hypoesthesia, dyesthesia, paraesthesia and anaesthesia. A better understanding of the anatomy of the inferior alveolar nerve to the mandibular posteriors may aid to decrease these reversible/irreversible damages to the inferior alve- olar nerve. Use of 2D imaging modalities such as intraoral periapical radiographs, orthopantographs have been commonly used to evaluate the surgical site. These forms of radiographs have their own limitations. Localization of critical anatomic structures at the surgical site using conventional radiographs leads to superimposition of overlying anatomy, distortion and magnification. These forms of radiographs are the 2-dimensional pictures of a 3 dimensional object.

Cone Beam Computed Tomography (CBCT) is a 3D imaging modality which is now increasingly utilized imaging tool in dentistry, allows the three dimensional reconstruction of maxillofacial structures in a fully scaled anatomical representation (Özkan Adigüzel et al. 2010) [4]. It is more accurate, sensitive and a noninvasive method of assessment of the maxillofacial structures as compared to the conventional methods.

To assess the proximity of the third molar to the inferior alveolar nerve canal, CBCT comes in handy. One can only estimate the proximity to the nerve canal by looking out or the radiographic signs seen on plain radiographs (IOPA \& OPG) whereas the exact measurement can be recorded using the coronal and the sagittal sections of the CBVI.

Various procedures in endodontics may lead to inferior alveolar nerve injury, a rare but serious treatment complication (Grötz 1998, Escoda-Francoli 2007) [5], [6]. It can result from the pressure phenomenon within the nerve canal (root canal medicaments), mechanical trauma (overzealous instrumentation), extru- 
sion of chemical agents (over filling by root canal obturation materials) and periapical surgery (Yatsuhashi $\mathrm{T}$ et al.2003) [7]. Hence it is important to know the exact location of the inferior alveolar nerve with respect to the surrounding structures to avoid any potential injury to the nerve. Hence, a study was undertaken to evaluate the proximity of the mandibular second premolar, first and the second molar to the superior border of the inferior alveolar nerve canal using CBCT so as to prevent any iatrogenic injuries to the inferior alveolar nerve bundle.

Many studies have been attempted by researchers. For ease of interpretation, the review of literature is expressed in a tabular form. (Table 1)

Table 1: Conclusion Drawn by Researchers to Evaluate the Proximity of IAN

\begin{tabular}{|c|c|c|}
\hline Year & Researcher & Conclusion \\
\hline 1992 & Denio $\mathrm{D}$ et $\mathrm{al}^{8}$ & $\begin{array}{l}\text { The second premolar \&second molar were the } \\
\text { closest to IAN. }\end{array}$ \\
\hline 2005 & Sato I et $\mathrm{al}^{9}$ & $\begin{array}{l}\text { First \& second molar were slightly closer to } \\
\text { IAN in females more than males. }\end{array}$ \\
\hline 2009 & $\begin{array}{l}\text { Simonton JD et } \\
\mathrm{al}^{10}\end{array}$ & $\begin{array}{l}\text { Distance to IAN from root apices was shorter } \\
\text { in females than in males. }\end{array}$ \\
\hline 2011 & $\begin{array}{l}\text { Tyler Kovisto } \\
\text { et al }{ }^{11}\end{array}$ & $\begin{array}{l}\text { Second molar was closer to IAN than second } \\
\text { premolar \& first molar. }\end{array}$ \\
\hline 2012 & $\begin{array}{l}\text { Özkan } \\
\text { Adigüzel et al }\end{array}$ & $\begin{array}{l}\text { Females had shorter distance from the root } \\
\text { apices to the IAN when compared to the } \\
\text { males. }\end{array}$ \\
\hline 2012 & $\begin{array}{l}\text { S M Balaji et } \\
\mathrm{al}^{13}\end{array}$ & $\begin{array}{l}\text { Distance to the IAN from root apices was } \\
\text { shorter in females than in males. }\end{array}$ \\
\hline 2015 & $\begin{array}{l}\text { Sebastian } \\
\text { Burklein et } \text { al }^{14}\end{array}$ & $\begin{array}{l}\text { Males had longer distances from root apices to } \\
\text { the IAN when compared to the females. }\end{array}$ \\
\hline 2015 & $\begin{array}{l}\text { B S Chong et } \\
\mathrm{al}^{15}\end{array}$ & Second molar was closest to IAN. \\
\hline 2016 & $\begin{array}{l}\text { Hemalatha et } \\
\text { al }^{16}\end{array}$ & $\begin{array}{l}\text { Distance was shorter for the females than in } \\
\text { males (bilateral) for second premolar, first } \\
\text { molar \&second molar. }\end{array}$ \\
\hline
\end{tabular}

Assessing the studies conducted above, present study was designed with following aims:

i). To estimate the distance between the apexes of the mesial root of the second premolar to the superior border of IAN.

ii). To estimate the distance between the apexes of the mesial root of the first molar to the superior border of IAN.

iii). To estimate the distance between the apexes of the mesial root of the second molar to the superior border of IAN.

iv). To assess the differences of all the parameters in both the genders to evaluate if this estimation can help in forensic methodology.

\section{Materials \& methods}

The study sample comprised of 150 individuals, out of which 78 were males and the rest 72 subjects were females. The CBCT scans were taken bilaterally for everyone. The scans were taken using KODAK 9000CBCT machine operated at $70 \mathrm{kVp}$ and $100 \mathrm{~mA}$. The patients in the age group of 16-80 years whose bilateral CBCT scans showing no development anomalies were prescribed: 1) to assess the degree of impaction in relation to the third molars and 2) to assess the extent of bone loss-were included within this study. Calibration of the linear measurement was performed using dimension in a millimeter. Two sections, i.e. coronal and sagittal section, were taken to locate the inferior alveolar nerve and the apex of the tooth. Using $200 \mu \mathrm{m}$ thick sections, the distance from the apex of the root to the superior border of the inferior alveolar nerve was determined. The mesial roots of the mandibular first and second molars along with the root of second premolar were taken into consideration. Measurements were recorded bilaterally for each patient.
Orange color - Inferior alveolar nerve

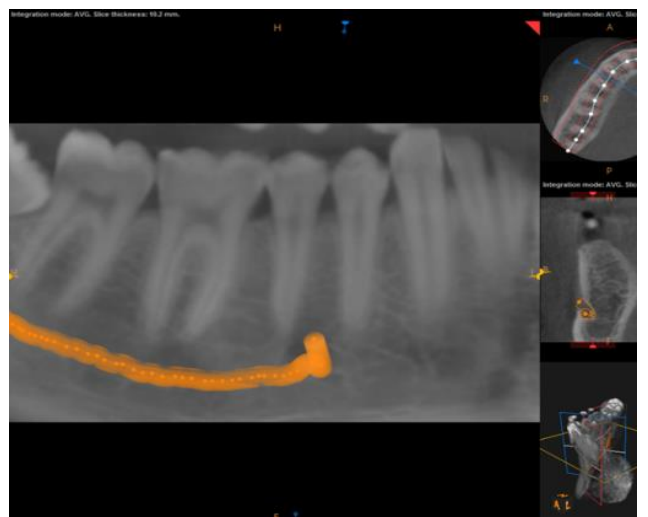

Fig. 1: Shows the Pan View of the Right Mandibular Posteriors

Green color - distance from the root apex of 2nd premolar up to the superior border of the IAN

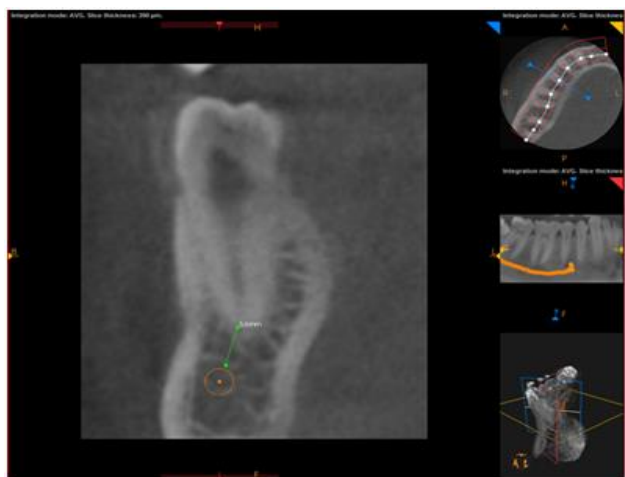

Fig. 2: Coronal Section of Right Second Premolar.

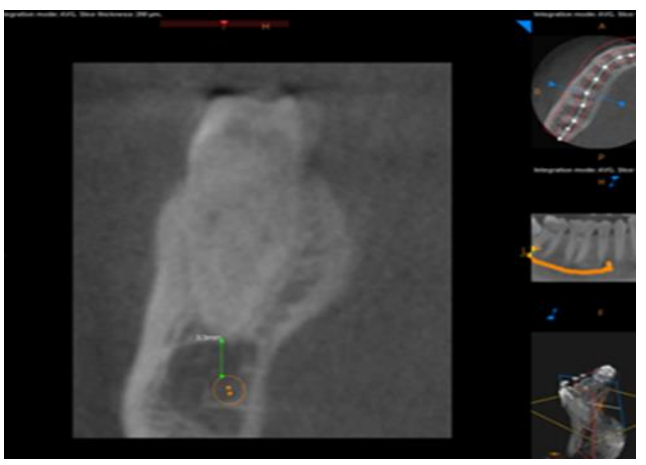

Fig. 3: Coronal Section of Right First Molar (Mesial Root)

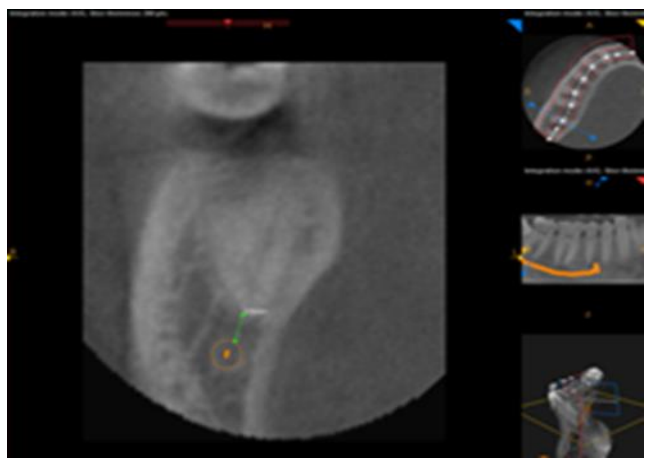

Fig. 4: Coronal Section of Right Second Molar (Mesial Root).

\section{Observation \& results}

All the data were analyzed using SPSS, version statistics of the variables and measurements are present using Students t- test (paired and unpaired). $\mathrm{p} \leq 0.05$ was taken as significant. 
Table 2: Composition of Study Population with Mean Age

\begin{tabular}{lll}
\hline Group & $\mathrm{n}$ & Mean Age \\
\hline Male & 78 & 30.76 \\
Female & 72 & 32.19 \\
\hline
\end{tabular}

Table 3: Value of $P$ in Males

\begin{tabular}{|c|c|c|c|c|c|c|}
\hline & & Paired Di & fferences & & & \\
\hline & $\begin{array}{l}\text { Tooth (bilat- } \\
\text { eral) }\end{array}$ & Mean & $\begin{array}{l}\text { Std. Devia- } \\
\text { tion }\end{array}$ & $\begin{array}{l}\text { Std. Error } \\
\text { Mean }\end{array}$ & value & df $\begin{array}{l}\mathrm{Sig} \cdot\left(2^{-}\right. \\
\text {tailed) }\end{array}$ \\
\hline $\begin{array}{l}\text { Pair } \\
1\end{array}$ & $\begin{array}{l}\text { second Premo- } \\
\text { lar (bilateral) }\end{array}$ & -2269231 & 1.8646174 & .2111264 & $-\overline{1.075}$ & 77.286 \\
\hline $\begin{array}{l}\text { Pair } \\
2\end{array}$ & $\begin{array}{l}\text { first Molar } \\
\text { (bilateral) }\end{array}$ & .1871795 & 1.5438490 & .1748065 & 1.071 & 77.288 \\
\hline $\begin{array}{l}\text { Pair } \\
3\end{array}$ & $\begin{array}{l}\text { second Molar } \\
\text { (bilateral) }\end{array}$ & .2564103 & 1.6532997 & .1871993 & $\overline{1.370}$ & 77.175 \\
\hline
\end{tabular}

The $\mathrm{p}$ value for the second premolar was found to be 0.286 , first molar being 0.0288 and for the second molar 0.175 . On comparing the values, the distance from the second molar to the IAN was the shortest from among the teeth.

Table 4: Value of $\mathrm{P}$ in Females

\begin{tabular}{|c|c|c|c|c|c|c|}
\hline & & Paired Di & fferences & & & \\
\hline & $\begin{array}{l}\text { Tooth (bilat- } \\
\text { eral) }\end{array}$ & Mean & $\begin{array}{l}\text { Std. Devia- } \\
\text { tion }\end{array}$ & $\begin{array}{l}\text { Std. Error } \\
\text { Mean }\end{array}$ & $\mathrm{t}$ & df $\begin{array}{l}\text { Sig. (2- } \\
\text { tailed) }\end{array}$ \\
\hline $\begin{array}{l}\text { Pair } \\
1\end{array}$ & $\begin{array}{l}\text { second Premo- } \\
\text { lar (bilateral) }\end{array}$ & -3111111 & 1.5947586 & .1879441 & $\begin{array}{l}- \\
1.655\end{array}$ & 71.002 \\
\hline $\begin{array}{l}\text { Pair } \\
2\end{array}$ & $\begin{array}{l}\text { first Molar } \\
\text { (bilateral) }\end{array}$ & -1208333 & 1.3400586 & .1579274 & -.765 & 71.044 \\
\hline $\begin{array}{l}\text { Pair } \\
3\end{array}$ & $\begin{array}{l}\text { second Molar } \\
\text { (bilateral) }\end{array}$ & .1111111 & 1.6128494 & .1900761 & .585 & 71.061 \\
\hline
\end{tabular}

The $\mathrm{p}$ value for the second premolar was found to be 0.002 , first molar 0.044 and that of second molar 0.061. The distance of the second premolar was the shortest to the inferior alveolar nerve in the females.

On comparing the values, we found that the distance between the root apices of second premolars, first and second molar was significantly shorter in females than in males (bilaterally). This finding comes in affirmation with the other studies that have been mentioned earlier.

\section{Discussion}

The mandibular canal harbors a thick nerve and vessels, typically located in close proximity to the root apices. Various surgical/ non-surgical procedural mishaps during root canal treatment pose iatrogenic cause of inferior alveolar nerve injury. If the sealer is extruded into the mandibular canal space, it can cause problems varying from mild inflammatory reactions to severe neurotoxic damage (Scolozzi 2004, Yamaguchi 2007) [17], [18].

Risk of injury to the inferior alveolar nerve during root canal treatment is dependent on several other factors; these include the (B. S. Chong et al. 2015) [15]:

i). Clinical angulation of the tooth

ii). Position of the anatomical foramen relative to the anatomical apex

iii). Presence of accessory foramina

iv). Presence/ absence of cementum around periapex

v). Quality and density of the trabecular bone

vi). The degree of cortication of IAN

If the canal is over prepared, and the apex opened chemical nerve injuries from irrigation of the canal is possible, as well as physical injury precipitated by overfilling using pressurized thermal techniques. The optimum $\mathrm{pH}$ of an endodontic medicament should be as close as possible to that of body fluids, i.e. around 7.35, as higher and lower pH's are likely to cause cellular necrosis of tissues in direct contact with the medicaments like formocresol, eugenol, iodoform paste, calcium hydroxide and sodium hypochlorite.
All root canal sealants have the potential to be neurotoxic, and if a radiograph shows sealant within the confines of the inferior alveolar canal, it is mandatory that the dentist monitors the patient during the post-operative period. Neurotoxic effect can be caused by an inflammatory reaction or allergic reaction. These reactions can cause action potential instability and reduced nerve conduction. If the causative agent were removed within 30 minutes, nerve conduction could regain stable amplitude. This indicates that the recovery from damage can be achieved by early removal of causative factors.

Third molar extractions are also one of the common causes of injury to the IAN. According to Renton T et al. 2005 [19], IAN injury was reported to occur in $3.6 \%$ of cases permanently and $8 \%$ temporarily. Proximities to the IAN canal and age are the most factors associated with IAN injury. Radiographs such as an IOPA \& OPG are usually taken to find out the proximity between the third molar and the IAN canal. Radiographic signs which are indicative of possible nerve risks are - darkening of the roots, loss of lamina dura of the IAN canal, deviation of the canal \& superimposition on the IAN canal. Having a CBVI scan taken for such regions would only help the clinician plan out an appropriate treatment plan such as - coronectomy, which would reduce the risk of damaging the IAN canal. Coronectomy avoids the nerve injury by ensuring the retention of the roots when they are close to the canal (as seen on radiographs).

Based on the study conducted by Tejas Shah et al.2014 [20], dental practioners showed favorable inclination towards a digital modes of imaging even when $65.37 \%$ of them used conventional radiography whereas the rest $35.62 \%$ used digital radiography. This shows the usage of 3D imaging only enhances the outcome of the radiographic imaging diagnosis.

\section{Conclusion}

To conclude, the distance between the root apices to the superior border of the IAN was shorter in females when compared with the males. This can be used to differentiate between gender and aid in forensics. More sample size, varying population are to be taken up, which will serve as a good guide for this observation.

\section{References}

[1] Carter RB, Keen EN. The intramandibular course of the inferior alveolar nerve. J Anat 1971; 108:433-40.

[2] Claeys V, Wackens G. Bifid mandibular canal: literature review and case report. DentomaxillofacRadiol 2005; 34:55-8. https://doi.org/10.1259/dmfr/23146121.

[3] Tara Renton. Prevention of Iatrogenic Inferior Alveolar Nerve Injuries in Relation to Dental Procedures. Dent Update 2010; 37: 350 363 https://doi.org/10.12968/denu.2010.37.6.350.

[4] Özkan Adigüzel, Senem Yiğit-Özer, Sadullah Kaya, Zeki Akkuş. Patient-specific factors in the proximity of the inferior alveolar nerve to the tooth apex Med Oral Patol Oral Cir Bucal. 2012 Nov 1; 17 (6):e1103-8. https://doi.org/10.4317/medoral.18190.

[5] Grötz KA, Al-Nawas B, de Aguiar EG, Schulz A, Wagner W. Treatment of injuries to the inferior alveolar nerve after endodontic procedures. Clin Oral Investig 1998; 2:73-6. https://doi.org/10.1007/s007840050048

[6] Escoda-Francoli J, Canalda-Sahli C, Soler A, Figueiredo R, Gay-Escoda C. Inferior alveolar nerve damage because of overextended endodontic material: A problem of sealer cement biocompatibility? J $\quad$ Endod2007; $33: 1484-9$. https://doi.org/10.1016/j.joen.2007.09.003.

[7] Yatsuhashi T, Nakagawa K, Matsumoto M, Kasahara M, Igarashi T, Ichinohe $\mathrm{T}$, et al. Inferior alveolar nerve paresthesia relieved by microscopic endodontic treatment. Bull Tokyo Dent Coll2003; 44:209-12. https://doi.org/10.2209/tdcpublication.44.209.

[8] Denio D, Torabinejad M, Bakland LK. Anatomical relationship of the mandibular canal to its surrounding structures in mature mandibles. J Endod 1992; 18: 161-5. https://doi.org/10.1016/S00992399(06)81411-1.

[9] Sato I, Ueno R, Kawai T, Yosue T. Rare courses of the mandibular canal in the molar regions of the human mandible: a cadaveric 
study. Okajimas Folia Anat Jpn 2005; 85: 95-101. https://doi.org/10.2535/ofaj.82.95.

[10] Simonton JD, Azevedo B, Schindler WG, Hargreaves KM. Ageand gender-related differences in the position of the inferior alveolar nerve by using cone beam computed tomography. J Endod. 2009; 35: 944-9. https://doi.org/10.1016/j.joen.2009.04.032.

[11] Tyler Kovisto, Mansur Ahmad, and Walter R. Bowles. Proximity of the Mandibular Canal to the Tooth Apex. J Endod 2011; 37: 311315. https://doi.org/10.1016/j.joen.2010.11.030.

[12] Özkan Adigüzel, Senem Yiğit-Özer, Sadullah Kaya, Zeki Akkus. Patient-specific factors in the proximity of the inferior alveolar nerve to the tooth apex. Med Oral Patol Oral Cir Bucal. 2012 Nov 1; 17 (6):e1103-8. https://doi.org/10.4317/medoral.18190.

[13] Balaji SM, Krishnaswamy NR, and Kumar SM, Rooban T. Inferior alveolar nerve canal position among South Indians: A cone beam computed tomographic pilot study. Ann Maxillofac Surg 2012; 2:51-5. https://doi.org/10.4103/2231-0746.95319.

[14] Sebastian Burklein, Carolin Grund and Edgar Schafer. Relationship between Root Apices and the Mandibular Canal: A Cone-beam Computed Tomographic Analysis in a German Population.J.Joen.2015.06.016.

[15] B. S. Chong, A. Quinn, R. R. Pawar, J. Makdissi \& S. K. Sidhu. The anatomical relationship between the roots of mandibular second molars and the inferior alveolar nerve. International Endodontic Journal, 48, 549-555, 2015. https://doi.org/10.1111/iej.12348.

[16] Hemalatha Hiremath, Rolly Agarwal, Vishwanath Hiremath, Tushar Phulambrikar. Evaluation of proximity of mandibular molars and second premolar to inferior alveolar nerve canal among central Indians: A cone-beam computed tomographic retrospective study.

[17] Scolozzi P, Lombardi T, Jaques B. Successful inferior alveolar nerve decompression for dysesthesia following endodontic treatment: Report of four cases treated with mandibular sagittal osteotomy. Oral SurgOral Med Oral Pathol Oral Radiol Endod 2004; 97:625-31. https://doi.org/10.1016/j.tripleo.2004.01.002.

[18] Yamaguchi K, Matsunaga T, Hayashi Y. Gross extrusion of endodontic obturation materials into the maxillary sinus: A case report. Oral SurgOral Med Oral Pathol Oral Radiol Endod 2007; 104:131-4. https://doi.org/10.1016/j.tripleo.2006.11.021.

[19] Renton T, Hankins M, Sproate C, McGurkM. A randomized controlled clinical trial to compare the incidence of injury to the inferior alveolar nerve as a result of coronectomy and removal of mandibular third molars. Br J Oral Maxillofac Surg 2005 Feb; 43(1): 7 12. https://doi.org/10.1016/j.bjoms.2004.09.002.

[20] Shah Tejas N, Pagare Sandeep S, Shetty Naveen, Vahanwal a Sonal. Digital radiography-A cutting edge in the dental practice: A survey. Indian Journal of Contemporary Dentistry2014, 2(1): 73- 75. https://doi.org/10.5958/j.2320-5962.2.1.015. 